\title{
A Rare Presentation of Popliteal Vein Aneurysm: Case Report
}

\author{
Ahmad Rezaee Azandaryani1, Pezhman Ghaderzadeh1, Leili Ebrahimi Farsangi2*, \\ Sayad Nasirzadeh ${ }^{3}$
}

${ }^{1}$ Radiology Department, Hamadan University of Medical Sciences, Besat Hospital, Hamadan, Iran

${ }^{2}$ Alborz University of Medical Sciences, Karaj, Iran

${ }^{3}$ Hamadan University of Medical Sciences, Besat Hospital, Hamadan, Iran

Email: Ahmad_rezaee20@yahoo.com, pejmanhsr92@gmail.com, ^lilieage@gmail.com, sayadnasirzadeh@yahoo.com

How to cite this paper: Azandaryani, A.R., Ghaderzadeh, P., Farsangi, L.E. and Nasirzadeh, S. (2017) A Rare Presentation of Popliteal Vein Aneurysm: Case Report. Case Reports in Clinical Medicine, 6, 19-23. http://dx.doi.org/10.4236/crcm.2017.61002

Received: November 28, 2016

Accepted: January 10, 2017

Published: January 13, 2017

Copyright $\odot 2017$ by authors and Scientific Research Publishing Inc. This work is licensed under the Creative Commons Attribution International License (CC BY 4.0).

http://creativecommons.org/licenses/by/4.0/

\begin{abstract}
Popliteal venous aneurysms (PVAs) are very rare. More often it is an incidental finding found on duplex ultrasonography. Venous thrombosis and pulmonary emboli is the primary presentation in most cases of PVAs, hence it is a clinically significant abnormality and a potentially morbid and fatal condition. Early surgical repair should be performed immediately after the diagnosis is made because of the risk of pulmonary emboli. We report a case of symptomatic PVA presenting primarily with local symptoms and chronic pain in popliteal region.
\end{abstract}

\section{Keywords}

Aneurysm, Popliteal Vein

\section{Introduction}

Popliteal venous aneurysms (PVAs) are very rare [1] [2]. More often it is an incidental finding found on duplex ultrasonography. Until 2000, 117 cases of PVAs have been reported in the literature, although its commonly asymptomatic nature warrants its actual prevalence to be higher [3]. In 7300 patients who presented with symptoms suggestive of venous disease PVA were diagnosed using duplex ultrasonography in $0.1 \%-0.2 \%$ of all studies [4]. Venous thrombosis and pulmonary emboli is the primary presentation in most cases of PVAs, hence it is a clinically significant abnormality and a potentially morbid and fatal condition. Also, its other complications such as paradoxical embolization and postthrombotic syndrome have been reported [3] [6]. However, we report a symptomatic case of PVA presenting with local symptoms and chronic pain in popliteal region. 


\section{Case Report}

A 38-year-old white male, previously healthy soccer player referred to our center for investigation of a chronic severe pain in the posterolateral region of the left knee and swelling in the left popliteal region. The patients' complaints had begun around 2.5 years ago. The pain was severe and disabling in the first year and then it was moderate and bearable. The pain was recurrent and occurred during routine daily activities and on palpation. The patient did not have any history of deep vein thrombosis, phlebitis and claudication but being a professional soccer player, our patient mentioned the history of recurrent trauma to legs and knee regions. Also, before the onset of the pain, the patient had experienced a trauma in the left knee while playing soccer. The patient in our case had undergone evaluations by orthopedics, physiatrists, neurologists and vascular surgeons prior to referral to our center. On physical examination, a small soft mass was present in the upper part of the left popliteal fossa, tenderness was also present on palpation. However, there were no signs of local inflammation and erythema, lower extremity edema and peripheral arterial angiopathy. Femoral, tibial and dorsalis pedis pulses of both sides were palpable. Head, neck, chest and abdomen examination, blood pressure, arterial oxygen saturation, chest radiography and electrocardiogram were normal. Noteworthy, according to knee joint magnetic resonance imaging, plain left knee radiography and physical examination performed by orthopedics, the patient was given reassurance that there was no pathology in the left knee joint that could explain and relate to our patients' complaints. Duplex ultrasonography was done for the patient on referral nearly 1 year after the onset of the symptoms, venous aneurysm with antero-posterior (AP) diameter of 16 milimiters was present in the left popliteal vein (Figure 1 and Figure 2).

Then the patient was referred to vascular surgeon for surgical care. The patient referred to two vascular surgery specialists, and they believed surgery was not indicated. The patient referred once again for follow up to our center around 1.5 years later (2.5 years after the onset of the symptoms). During this period the patient had still experienced pain and mild swelling in the left popliteal region

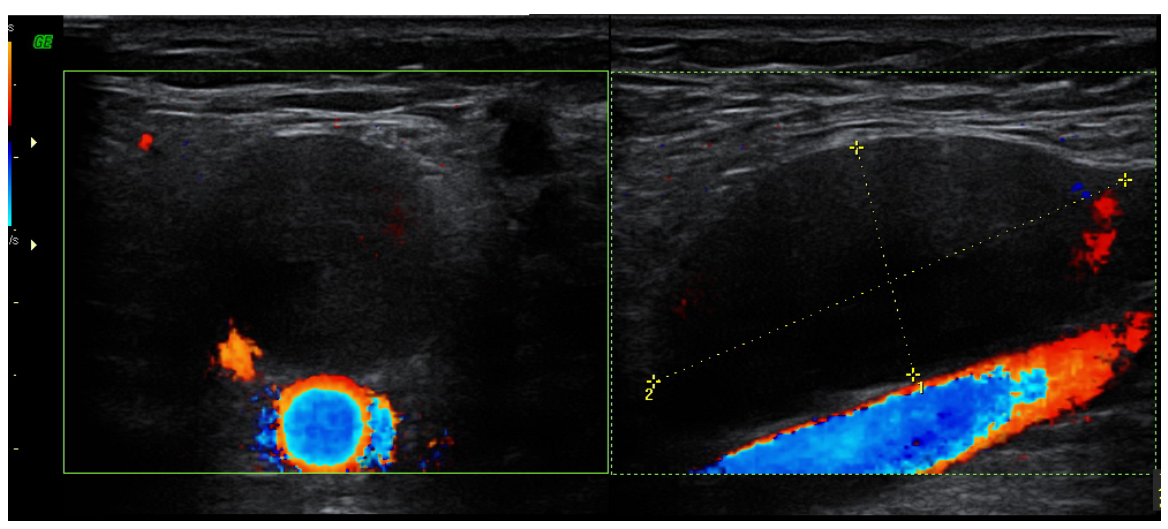

Figure 1. Axial and sagittal color duplex ultrasonographic images of left popliteal cavity before calf veins squeezing demonstrates echo free popliteal aneurysm anterior to popliteal artery. 


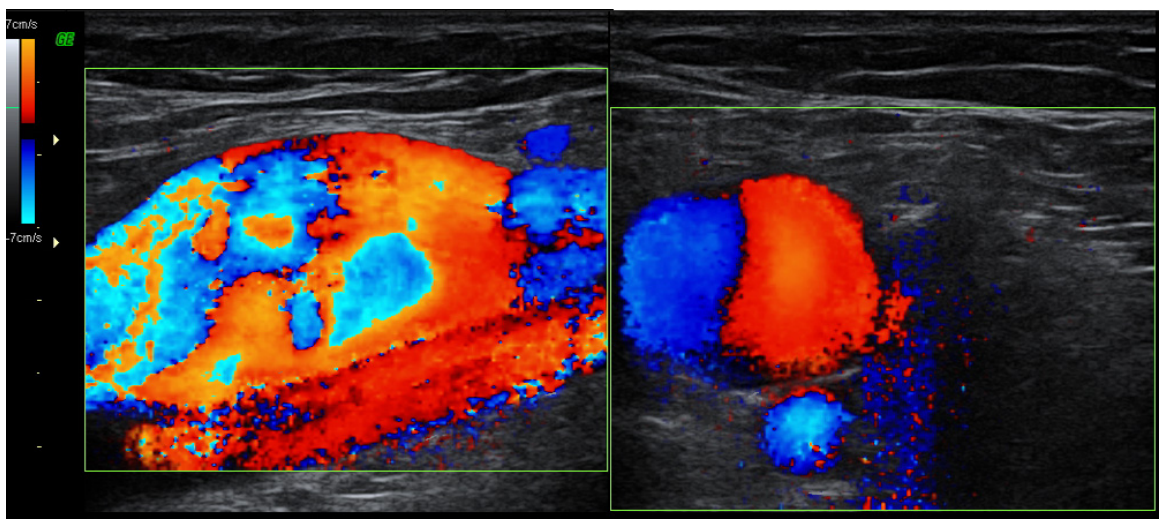

Figure 2. Axial and sagittal color duplex ultrasonographic images of left popliteal cavity after calf veins squeezing demonestrates popliteal aneurysm anterior to popliteal artery.

which was milder and denied any history or signs related to severe complications of PVAs such as deep vein thrombosis or pulmonary emboli. We performed duplex ultrasonography once again plus magnetic resonance imaging (MRI) which this time revealed an AP diameter of 19milimiters in the left popliteal vein (Figure 3).

Urgent surgical management was recommended for the patient and the patient was referred to vascular surgery specialists as the next step in care. Noteworthy, informed consent was obtained from our patients regarding case report publication and there was no objection.

\section{Discussion}

Popliteal venous aneurysms are extremely uncommon abnormality with an incidence of almost $<0.5 \%$ [7]. PVA is a true aneurysm which consists of intact vessel wall [8]. However, popliteal venous aneurysms still lack an exact definition. Different definitions such as fusiform dilatation at least three times that of normal vein [9] and isolated venous dilatation twice the normal venous diameter have been recommended [10]. In our case, the popliteal aneurysm was saccular type. Inflammation, trauma, degenerative changes and congenital wall weakness may be some of the probable etiologies for PVAs [11]. Nearly all cases of PVAs are diagnosed after patients present with complications due to PVA, deep vein thrombosis and pulmonary emboli being the most common of all [12] [13] [14]. However, in our case, chronic posterolateral left knee pain and local sign such as mild swelling in the popliteal region was the primary presentation. PVAs presenting with knee pain and local symptoms is reported by some other authors too [15] [16] [17]. Coffman et al. reported a case with recurrent sharp and severe pain in the popliteal fossa which was later revealed to be due to PVA [17]. Fiori et al. reported a case with local discomfort in the left popliteal fossa during daily activities and palpation [16]. In a meta-analysis knee pain and popliteal mass was reported as the clinical presentation secondary to PVA in 35\% of cases [4]. Being a soccer player, we believe that trauma may be the probable cause for popliteal aneurysm in our case. Duplex ultrasonography, computed tomography scanning, and magnetic resonance imaging are non-invasive diagnostic methods 


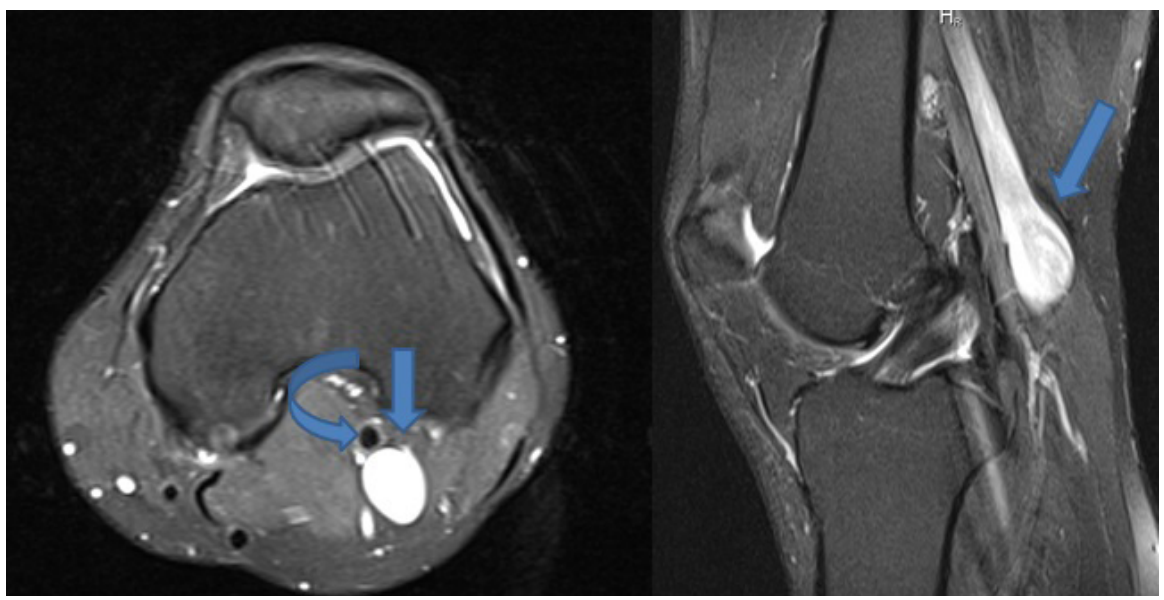

Figure 3. Axial and sagittal fat suppresed proton density MRI images demonstrates left popliteal aneurysm (arrows) posterior to popliteal artery (curved arrow).

applicable in diagnosis of PVAs. Duplex ultrasonography can be used as the initial detection technique because it is non-invasive, inexpensive and conveniently repeatable [18]. Also, ultrasonography could rule out PVAs differential diagnosis such as Baker's cyst and tibiofibular joint cysts.

Surgery is believed to be the gold standard option in treatment of PVAs regardless of being symptomatic or not. Some of the surgical treatment options of symptomatic and asymptomatic cases are resection with end-to-end anastomosis, tangential aneurysmectomy, resection with interposition graft and ligation of the proximal and distal vein. Early post-surgical patency rates are high and there has not been any report regarding recurrent pulmonary embolism post-surgery, however the long-term consequences of surgical repair is not known [3] [19].

\section{Conclusion}

Popliteal venous aneurysm is a very uncommon abnormality but due its severe consequences such as deep vein thrombosis and pulmonary emboli, it is potentially fatal. This case report demonstrates knee pain and local discomfort as one of the presenting symptoms for PVAs. Therefore, after ruling out more common causes, PVAs should be considered in a patient with chronic knee pain and local discomfort, especially if it is accompanied with swelling. Early surgical repair should be performed immediately after the diagnosis is made because of risk of pulmonary emboli.

\section{References}

[1] Sarap, M.D. and Wheeler, W.E. (1988) Venous Aneurysms. Journal of Vascular Surgery, 8, 182-183. https://doi.org/10.1016/0741-5214(88)90407-7

[2] Friedman, S.G., Krishnasastry, K.V., Doscher, W. and Deckoff, S.L. (1990) Primary Venous Aneurysms. Surgery, 108, 92-95.

[3] Sessa, C., Nicolini, P., Perrin, M., Farah, I., Magne, J.L. and Guidicelli, H. (2000) Management of Symptomatic and Asymptomatic Popliteal Venous Aneurysms: A Retrospective Analysis of 25 Patients and Review of the Literature. Journal of Vas- 
cular Surgery, 32, 902-912. https://doi.org/10.1067/mva.2000.110353

[4] Bergqvist, D., Bjorck, M. and Ljungman, C. (2006) Popliteal Venous Aneurysm-A Systematic Review. World Journal of Surgery, 30, 273-279.

https://doi.org/10.1007/s00268-005-7982-y

[5] Winchester, D., Pearce, W.H., McCarthy, W.J., McGee, G.S. and Yao, J.S. (1993) Popliteal Venous Aneurysms. Surgery, 114, 600-607.

[6] Willinek, W.A., Strunk, H., Born, M., Remig, J., Becher, H. and Schild, H. (2001) Popliteal Venous Aneurysm with Paradoxical Embolization in a Patient with Patent Foramen Ovale. Circulation, 104, E60-E61. https://doi.org/10.1161/hc3701.095641

[7] Labropoulos, N., Volteas, S.K., Giannoukas, A.D., Touloupakis, E., Delis, K. and Nicolaides, A.N. (1996) Asymptomatic Popliteal Vein Aneurysms. Vascular and Endovascular Surgery, 30, 453-457. https://doi.org/10.1177/1538574449603000602

[8] Chahlaoui, J., Julien, M., Nadeau, P., Bruneau, L., Roy, P. and Sylvestre, J. (1981) Popliteal Venous Aneurysm: A Source of Pulmonary Embolism. AJR American journal of Roentgenology, 136, 415-416. https://doi.org/10.2214/ajr.136.2.415

[9] Maleti, O., Lugli, M. and Collura, M. (1997) Anevrysmes veineux poplites: Experience personnelle: Les anévrysmes veineux de la fosse poplitée (à l'exclusion de la veine saphène externe). Phlebologie, 50, 53-59.

[10] McDevitt, D.T., Lohr, J.M., Martin, K.D., Welling, R.E. and Sampson, M.G. (1993) Bilateral Popliteal Vein Aneurysms. Annals of Vascular Surgery, 7, 282-286. https://doi.org/10.1007/BF02000255

[11] Hong, D. and Song, S.W. (2013) Pulmonary Embolism Caused by Popliteal Venous Aneurysm. The Korean Journal of Thoracic and Cardiovascular Surgery, 46, 76-79. https://doi.org/10.5090/kjtcs.2013.46.1.76

[12] Grice, G.D., Smith, R.B., Robinson, P.H. and Rheudasil, J.M. (1990) Primary Popliteal Venous Aneurysm with Recurrent Pulmonary Emboli. Journal of Vascular Surgery, 12, 316-318. https://doi.org/10.1016/0741-5214(90)90154-3

[13] Dawson, K. and Hamilton, G. (1991) Primary Popliteal Venous Aneurysm with Recurrent Pulmonary Emboli. Journal of Vascular Surgery, 14, 437. https://doi.org/10.1016/0741-5214(91)90141-G

[14] Lang, E., Bouwman, O. and Faiss, J. (1993) Recurrent Lung Embolisms in Aneurysm of the Popliteal Vein. Der Chirurg, Zeitschrift fur alle Gebiete der operativen Medizen, 64, 503-504.

[15] Premaratne, S., Tan, T.W., Coulter, A.H., Doumite, D. and Zhang, W.W. (2014) Symptomatic Popliteal Vein Aneurysm. Vascular and Endovascular Surgery, 48, 275-276. https://doi.org/10.1177/1538574413518608

[16] Fiori, R., Chiappa, R., Gaspari, E. and Simonetti, G. (2010) A Rare Case of Popliteal Venous Aneurysm. Case Reports in Medicine, 2010, Article ID: 579256. https://doi.org/10.1155/2010/579256

[17] Coffman, S.W., Leon, S.M. and Gupta, S.K. (2000) Popliteal Venous Aneurysms: Report of an Unusual Presentation and Literature Review. Annals of Vascular Surgery, 14, 286-290. https://doi.org/10.1007/s100169910050

[18] Seino, Y., Fujimori, H., Shimai, S., Tanaka, K., Takano, T., Hayakawa, H., et al. (1994) Popliteal Venous Aneurysm with Pulmonary Embolism. Internal Medicine, 33, 779-782. https://doi.org/10.2169/internalmedicine.33.779

[19] Gallagher, J.J. and Hageman, J.H. (1985) Popliteal Vein Aneurysm Causing Pulmonary Embolus. Archives of Surgery, 120, 1173-1175. 
Submit or recommend next manuscript to SCIRP and we will provide best service for you:

Accepting pre-submission inquiries through Email, Facebook, LinkedIn, Twitter, etc. A wide selection of journals (inclusive of 9 subjects, more than 200 journals)

Providing 24-hour high-quality service

User-friendly online submission system

Fair and swift peer-review system

Efficient typesetting and proofreading procedure

Display of the result of downloads and visits, as well as the number of cited articles Maximum dissemination of your research work

Submit your manuscript at: http://papersubmission.scirp.org/

Or contact crcm@scirp.org 